\title{
Measuring equal increments of utility for money without measuring utility itself'
}

EDWARD LOEWENTON AND R. DUNCAN LUCE

UNIVERSITY OF PENNSYLVANIA
Let $(A, P)$ denote the commodity bundle consisting of $\$ A$ and some other commodity $\mathrm{P}$. With $\mathrm{P}$ and $\mathrm{Q}$ fixed, then for any $A$ determine that $B$ for which $S$ is indifferent between $(A, P)$ and $(B, Q)$. If utility is additive over the components, each money difference induces the same utility difference. Two choices for $\mathrm{P}$ and $\mathrm{Q}$, all jazz records of equal monetary value, and two levels for $A, 534$ and $\$ 5.03$, were studied. One $S$ did not maintain consistent indifference points, two exhibited constant marginal utility, and two exhibited diminishing marginal utility.

Marginal utility of money is generally believed to be a diminishing function of money, i.e., the increment of utility created by adding $\$ 1$ to $\$ 100$ is less than that created by adding $\$ 1$ to $\$ 10$. Supporting evidence is strong introspective feelings and sophisticated, but indirect economic arguments. In the few experimental studies (Davidson, Suppes, \& Siegel, 1957; Edwards, 1955; Mosteller \& Nogee, 1951) where utility functions have been constructed, increasing, constant, and diminishing marginal utility have all been found. In each case, the money range was narrow, gambles were used, and, to varying degrees, the expected utility hypothesis was assumed. If one has misgivings, as many do, about that hypothesis, it is difficult to know how seriously to take the resulting functions.

Our purpose, largely methodological, is to establish the feasibility of an alternative experimental approachone that is at least as direct, avoids gambles and the expected utility hypothesis, and does not require the construction of utility functions. We know of no method that is totally free from auxiliary assumptions, but at least we use a different one, namely, that for some two-component commodity bundles, utility is additive over the components. Since well-known examples make it clear that such additivity is not universally true, it is important to select a second component that probably is treated as independent of money. Plausible possibilities are a component that consists of either nonexchangeable outcomes (e.g., shock) or of commodities that have the same monetary value. We elected the latter.

With money the first component, let $A$ be a fixed sum of money, and let $P$ and $Q$ denote any two elements of the second component, with $P$ less preferred than $Q$. Then determine that sum of money, B, presumably larger than $A$, such that $S$ judges the bundle $(B, P)$ to be indifferent to $(A, Q)$. Assuming utility is additive, the utility difference $u(B)-u(A)$ equals the utility difference $u(Q)-u(P)$. Holding $P$ and $Q$ fixed, we may select different values for $A$ and determine the corresponding $B^{\prime}$ s-we used only two levels, low (1) and high (h). Since both of the utility-of-money differences are equal to the same utility difference on the second component, they are equal. (This idea was exploited theoretically by Luce \& Tukey (1964).) Of course, the money differences, $\Delta_{1}=B_{1}-A_{1}$ and $\Delta_{h}=B_{h}-A_{h}$, need not be equal. The marginal utility at $A_{h}$ is $>,=$, or $<$ than that at $A_{l}$ if $\Delta_{h}<,=$, or $>\Delta_{l}$.

The only subtle experimental problem is how to determine $B$ when $A, P$, and $Q$ are given. We elected to find its approximate value by asking $S$ to judge itthis estimate is denoted $\bar{B}$-and then we repeatedly presented choices between $(\dot{B}+\delta, P)$ and $(A+c, Q)$ where $\delta$ and $\epsilon$ are small positive and negative sums of money. Assuming local linearity of utility, only money differences matter and so we may plot the relative frequency of choosing the former bundle as a function of $\tilde{B}+\delta-A-\epsilon=\tilde{\Delta}+(\delta-\epsilon)$. The estimated $50 \%$ point yields an estimate of the money difference corresponding to indifference, $\hat{\Delta}$.

\section{Method}

Four male university undergraduates and a female secretary (S3) with a taste for and familiarity with jazz music were the Ss. They were paid $\$ 3$ and each received a jazz record.

On the basis of an informal poll, 14 jazz records of approximately the same monetary value were selected

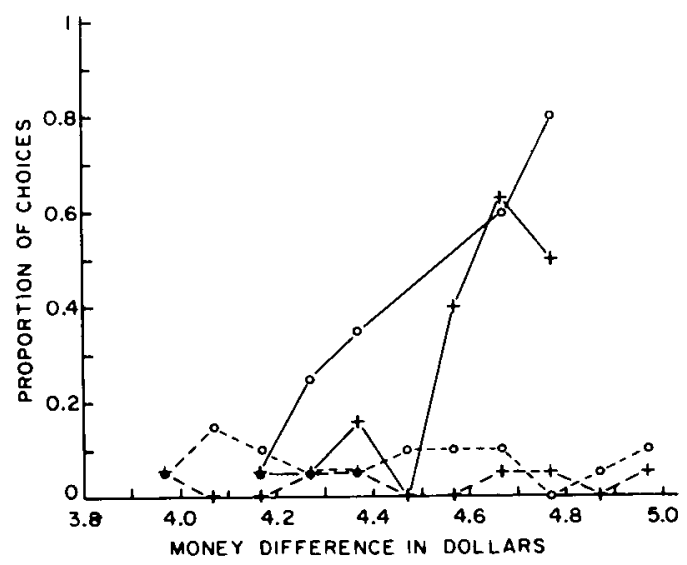

Fig. 1. For $\mathrm{S} 1$, the proportion of times that the commodity bundle including the less preferred record was selected as a function of the money difference between the two bundles. There are from 10 to 20 observations per point. Circles represent data involving records $\mathbf{R}_{6}$ and $\mathbf{R}_{9}$; crosses $R_{5}$ and $Q^{\prime}$; solid lines, the lower money levels; and dotted lines, the higher money levels. 


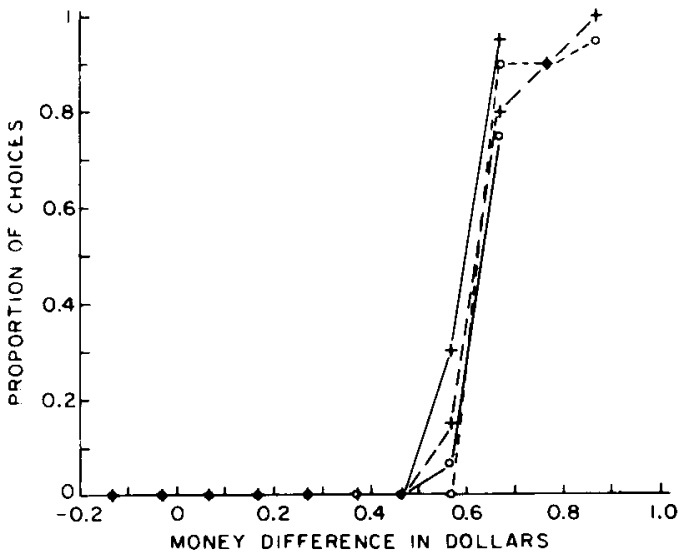

Fig. 2. For 52 , the same as Fig. 1.

as being generally popular among the initiated. Each $s$ was able to select a subset of 10 that he considered desirable, and he arranged the records themselves in order of preference under instructions that this together with his choices in the second session would, in part, determine the record he would receive. Let $R_{i}$ denote that record to which $\mathrm{S}$ assigned rank $\mathrm{i}$. With $\mathrm{P}=\mathrm{R}_{9}$, $Q=R_{6}$, and $\lambda_{1}=53^{\$}$, s was asked to state the value $\bar{B}_{1}$ for which $\left(B_{1}, P\right)$ seemed indifferent to $\left(A_{1}, Q\right)$. Then, with $P^{\prime}=R_{5}$, he was asked to select that record, $Q^{\prime}$, from among the 10 so that, as nearly as possible, $\left(A_{l}, Q^{\prime}\right)$ was indifferent to $\left(\dot{B}_{l}, P^{\prime}\right)$. Since only four records were conceivable choices, it was most unlikely that a real indifference had been found; hence $S$ was asked to adjust $B$ to that value, $\bar{B}^{\prime}{ }_{1}$, for which perfect indifference was achieved. This ended the first session.

The second session occurred the following day for all $\mathrm{Ss}$ save $\mathrm{S} 4$ who was delayed a week. Between sessions, cards with pairs of bundles were prepared as follows. For $A_{1}, \hbar=0,{ }^{t} 10 \notin, \pm 20 \varsigma, \pm 30 \$$ were paired with $f=0$, and $r= \pm 10^{\star}, \pm 20 \notin, \pm 30 \notin$ with $\delta=0$, which produced 13 comparisons in each condition. For the higher level we set $\lambda_{h}=\$ 5.03$ and took $\dot{B}_{h}=A_{h}+\bar{I}_{l}$, where $i_{1}=\dot{B}_{1}-A_{1}$, and similarly for the primed condition. This is a reasonable guess for $B_{h}$ only if utility is approximately linear with money. The choices of $\hat{b}$ and $f$ were those above with $\pm 10 \phi$ and $\pm 50 \phi$ added, which yielded 21 comparisons in each condition. Each

Table I. Fstimates of money differences, at two different monetary levels, that create indifference between commodity bundles. Marginal utility is increasing. constant or decreasing if $\downarrow_{h}-l_{l},=$, or $>0$.

\begin{tabular}{|c|c|c|c|c|c|c|c|c|}
\hline & \multirow{2}{*}{\multicolumn{7}{|c|}{ Records }} \\
\hline & & \multicolumn{2}{|c|}{$P$ and $Q$} & & & \multicolumn{2}{|c|}{$P^{\prime}$ and $G^{\prime}$} & \\
\hline & & & $i_{h}$ & $\hat{i}_{h}-\hat{i}_{l}$ & $i_{l}^{\prime}$ & i. & 涪 & $i_{h}-\hat{\alpha} ;$ \\
\hline 1 & 4.47 & 4.55 & $>4.97$ & 0.42 & 4.47 & 4.61 & $>4.97$ & $>0.36$ \\
\hline 2 & 0.37 & 0.63 & 0.62 & -0.01 & 0.37 & 0.60 & 0.62 & +0.02 \\
\hline 3 & 4.47 & $<4.17$ & $\geq 4.94$ & $>0.77$ & 2.47 & 4.04 & $\geq 4.57$ & $\geq 0.53$ \\
\hline 5 & 0.17 & 0.61 & 0.59 & -0.02 & 0.07 & 20.57 & 0.79 & $\leq 0.13$ \\
\hline
\end{tabular}

comparison was repeated five times in each order, for a total of 680 cards. Note that each monetary difference was repeated 20 times. The order of presentation was randomized by thoroughly shuffling the cards.

As it turned out, two Ss had such non-linear utility functions that the range of $\pm 50 \$$ about $A_{h}$ failed to include the choice indifference point, and the same was true for three Ss in the range of $\pm 30 \%$ about $A_{1}$. When this difficulty became apparent during the session, some of the useless comparisons were dropped and new ones in the range of interest were added. This led to some variation in sample sizes; we report only data points based upon at least 10 comparisons.

\section{Results}

The relative frequencies of selecting the bundle with the less preferred record, $\mathrm{P}$ or $\mathrm{P}^{\prime}$, as a function of the monetary difference are plotted for Ss 1 and 2 in Figs. 1 and 2. The curves of S3 are similar to those of S1, and those of $\mathrm{S} 5$ to those of S2. The data from S4 were not useable because he did not maintain fixed indifference points during the session; this he reported, and it was confirmed by examining the data separated by thirds. The other four Ss were not excessively variable according to this criterion. From these curves, $\hat{\imath}_{1}$ and $\hat{i}_{h}$ were estimated by eye-the results are so clear that no more subtle method is necessary. They are given in Table 1 .

First, it is evident that Ss 1 and 3 exhibit sharply diminishing marginal utility and that Ss 2 and + have a constant marginal utility in the $\$ 4.50$ range studied. Second, the judged indifference points, $i_{1}$, of three of these four Ss did not accord especially well with the ones, $\hat{i}_{l}$, estimated from their choices. Finally, it is notable that the two Ss who established indifference with a money difference in excess of $\$ 4$ had diminishing marginal utility, whereas the two with a difference of less than $\$ 1$ had constant marginal utility. It is impossible to guess whether this will hold up in a large sample.

In summary, these data suggest that is it feasible to construct equal increments of utility for monty using the proposed method and, hence, feasible to decide what type of marginal utility an individual $\mathrm{S}$ has without constructing his entire utility function.

\section{References}

Davidson. D.. Suppes. P.. \& Siegel. S. Décision-making: an \&. perimental approach. Stanford: Stanford University Press, 1957.

Edwards, $\boldsymbol{W}$. The prediction of decisions among bets. $J$. exp. Psuchol., 1955, 50, 201-214.

Luce, R. D., \& Tukey, J. Simultaneous conjoint measurement: a new type of fundamental measurement. J. math. Psychol., 1964, 1. $1-27$.

Mosteller, F., \& Nogee, P. An experimental measurement of utility. J. pol. Econ., 1951, 59, 371-404.

\section{Note}

1. This work was supported in part by National Science Foundation grant NSF GB 1462. We are indebted to Dr. F. W. Irwin for his comments. 